\title{
Reduced hippocampal neurogenesis in R6/2 transgenic Huntington's disease mice
}

\author{
Joana M.A.C. Gil, ${ }^{\text {a,b }}$ Paul Mohapel, ${ }^{a}$ Inês M. Araújo, ${ }^{\text {a,c }}$ Natalija Popovic, ${ }^{a}$ Jia-Yi Li, ${ }^{a}$ \\ Patrik Brundin, ${ }^{\mathrm{a}}$ and Åsa Petersén ${ }^{\mathrm{a}, *}$ \\ ${ }^{a}$ Neuronal Survival Unit, Wallenberg Neuroscience Center, Department of Experimental Medical Sciences, Lund University, BMC A10, \\ SE-221 84 Lund, Sweden \\ ${ }^{\mathrm{b}}$ Center for Neurosciences and Cell Biology and Institute of Biochemistry, Faculty of Medicine, University of Coimbra, 3004-504 Coimbra, Portugal \\ ${ }^{c}$ Center for Neurosciences and Cell Biology and Department of Zoology, University of Coimbra, 3004-517 Coimbra, Portugal
}

Received 9 December 2004; revised 4 May 2005; accepted 6 May 2005

Available online 13 June 2005

\begin{abstract}
We investigated whether cell proliferation and neurogenesis are altered in R6/2 transgenic Huntington's disease mice. Using bromodeoxyuridine (BrdU), we found a progressive decrease in the number of proliferating cells in the dentate gyrus of $\mathrm{R} 6 / 2$ mice. This reduction was detected in pre-symptomatic mice, and by 11.5 weeks, R6/2 mice had $66 \%$ fewer newly born cells in the hippocampus. The results were confirmed by immunohistochemistry for the cell cycle markers Ki-67 and proliferating cell nuclear antigen (PCNA). We did not observe changes in cell proliferation in the $\mathbf{R} 6 / 2$ subventricular zone, indicating that the decrease in cell proliferation is specific for the hippocampus. This decrease corresponded to a reduction in actual hippocampal neurogenesis as assessed by double immunostaining for $\mathrm{BrdU}$ and the neuronal marker neuronal nuclei (NeuN) and by immunohistochemistry for the neuroblast marker doublecortin. Reduced hippocampal neurogenesis may be a novel neuropathological feature in $\mathrm{R} 6 / 2$ mice that could be assessed when evaluating potential therapies.

(c) 2005 Elsevier Inc. All rights reserved.
\end{abstract}

Keywords: BrdU; Cell proliferation; Dentate gyrus; Doublecortin; Huntington's disease; Ki-67; Neurogenesis; R6/2 mice; PCNA; Subventricular zone

\section{Introduction}

Huntington's disease (HD) is an autosomal dominant neurodegenerative disorder caused by an expanded CAG repeat in the

Abbreviations: AD, Alzheimer's disease; ANOVA, analysis of variance; BDNF, brain-derived neurotrophic factor; BrdU, bromodeoxyuridine; DG, dentate gyrus; HD, Huntington's disease; NeuN, neuronal nuclei; NHS, normal horse serum; NSS, normal swine serum; PBS, phosphate buffer saline; PCNA, proliferating cell nuclear antigen; PD, Parkinson's disease; SGZ, subgranular zone; SVZ, subventricular zone.

* Corresponding author. Fax: +46 462220531.

E-mail address: asa.petersen@mphy.lu.se ( $₫$. Petersén).

Available online on ScienceDirect (www.sciencedirect.com).
$H D$ gene, which encodes for huntingtin, a large cytoplasmic protein of yet unknown function (HDCRG, 1993). The disease is invariably fatal and affected individuals show depression, a severe motor impairment, dementia, and weight loss. The neuropathology of the disease is characterized by accumulation of huntingtin in neuronal intranuclear inclusions, as well as a progressive degeneration of neurons in the striatum, certain layers of the cerebral cortex, and the hypothalamus (for review, Petersén and Brundin, 2002; Vonsattel and DiFiglia, 1998). The most used animal model for studying the mechanisms underlying the pathogenesis of HD is the R6/2 transgenic mouse model, which expresses exon 1 of human mutant $H D$ gene with approximately 150 CAG repeats (Mangiarini et al., 1996). R6/2 mice display several features of the human condition, including progressive motor (Carter et al., 1999) and cognitive impairments (Lione et al., 1999; Murphy et al., 2000), weight loss, decreased striatal and brain size (Mangiarini et al., 1996), ubiquitinated nuclear and cytoplasmic inclusions of mutant huntingtin (Davies et al., 1997), altered levels of neurotransmitters (Cha, 2000) and their receptors (Cha et al., 1998), decreased expression of striatal signaling genes (Luthi-Carter et al., 2000), and premature death (Mangiarini et al., 1996). Relatively little neuronal death has been detected in the striatum and cerebral cortex of R6/2 mice (Iannicola et al., 2000; Turmaine et al., 2000). However, we recently described a progressive loss of orexin neurons in the lateral hypothalamus of these transgenic HD mice (Petersén et al., 2005). A loss of retinal ganglion neurons has also been reported (Helmlinger et al., 2002).

Although initially thought to occur only during embryonic development, recent studies have shown that neurogenesis occurs throughout life and that there are significant numbers of neural precursors in several regions of the adult mammalian brain. In fact, proliferation and differentiation of new neurons are now known to occur in selective regions of the adult brain, primarily in the subventricular zone (SVZ) of the lateral ventricles and in the subgranular zone (SGZ) of the dentate gyrus (DG) of the hippocampus. Given this capacity of the adult brain to generate 
new neurons, adult neuronal stem cells have been proposed as an endogenous source of healthy cells for the treatment of certain neurodegenerative diseases (for review, Lie et al., 2004; Mohapel and Brundin, 2004). Also, it is not completely understood to what extent the neurogenic process is altered in neurodegenerative conditions since different groups have reported contradictory results regarding alterations in neurogenesis in animal models and patients of various disorders including Alzheimer's disease (AD) (Haughey et al., 2002a,b; Jin et al., 2004a,b) and Parkinson's disease (PD) (Fallon et al., 2000; Frielingsdorf et al., 2004; Hoglinger et al., 2004; Zhao et al., 2003). In a recent report by Curtis et al. (2003), an increase in cell proliferation and neurogenesis in the SVZ of HD patients was described. We have recently found that cell proliferation is reduced in the DG of end-stage R6/2 mice (Gil et al., 2004). This is in agreement with a study by Lazic et al. (2004), which showed a reduction in hippocampal cell proliferation in R6/1 transgenic HD mice.

In the present study, we extend our previous observations, by using several different markers to evaluate cell proliferation and neurogenesis during the lifespan of R6/2 mice. Our results demonstrate a dramatic decrease of cell proliferation in the DG but not in the SVZ of these mice. This decrease can be detected already at an early age. Furthermore, by using confocal microscopy, we also showed that the reduction in hippocampal cell proliferation corresponds to an actual decrease in the generation of new neurons.

\section{Materials and methods}

\section{Transgenic mice}

Transgenic HD mice of the R6/2 line were originally purchased from Jackson Laboratories (Bar Harbor, ME, USA) and the colony was maintained by breeding heterozygous R6/2 males with females from their background strain $(\mathrm{F} 1$ of $\mathrm{CBA} \times \mathrm{C} 57 \mathrm{Bl} / 6)$. Tails of the offspring were used to obtain DNA for determination of the genotype using a polymerase chain reaction assay (Mangiarini et al., 1997). The mice were housed in groups with ad libitum access to food and water at a 12-h light/dark cycle. All experimental procedures conducted in this study were approved by the Ethical Committee at Lund University.

\section{Treatments and tissue processing}

Generation of newborn cells was assessed by injecting $50 \mathrm{mg} /$ $\mathrm{kg}$ of the thymidine analogue bromodeoxyuridine (BrdU, in phosphate buffer saline, PBS, pH 7.2; Sigma, Steinheim, Germany) i.p. every $12 \mathrm{~h}$ for 3 consecutive days. At 3.5, 7.5, and 11.5 weeks of age, mice were sacrificed $18 \mathrm{~h}$ after the last BrdU injection. To analyze the neuronal differentiation of the newborn cells that incorporated BrdU, a separate set of mice at the age of 5.5 and 10 weeks were sacrificed 2 weeks after the last BrdU injection, which was administered at 3.5 and 8 weeks of age, respectively. Mice at 2 weeks of age were sacrificed without prior BrdU injection due to their young age. Mice were deeply anesthetized with pentobarbital and transcardially perfused with saline followed by paraformaldehyde (4\%) in $0.1 \mathrm{M}$ PBS. The brains were left in fixative overnight and then dehydrated in $20 \%$ sucrose/ $0.1 \mathrm{M}$ phosphate buffer. Six series of coronal sections were cut throughout the brain on a sliding microtome at a thickness of $30 \mu \mathrm{m}$.

\section{Immunohistochemistry}

One series of free-floating sections was processed for BrdU immunohistochemistry. Briefly, the sections were incubated in $1 \mathrm{M}$ $\mathrm{HCl}$ at $65^{\circ} \mathrm{C}$ for $30 \mathrm{~min}$ in order to denaturate the DNA. The sections were then preincubated for $1 \mathrm{~h}$ in $5 \%$ normal horse serum (NHS) and $0.25 \%$ Triton X-100 in PBS and then incubated for $48 \mathrm{~h}$ at $4{ }^{\circ} \mathrm{C}$ with a mouse monoclonal antibody against BrdU (1:50; Dako, Glostrup, Denmark) in PBS containing 2\% NHS. After incubation with a biotinylated horse anti-mouse secondary antibody (1:200; Dakopatts, Copenhagen, Denmark) for $2 \mathrm{~h}$, the bound antibodies were visualized using an avidin-biotin-peroxidase complex system (Vectastain ABC Elite Kit, Vector Laboratories, Burlingame, CA, USA).

Separate series of sections were also processed for detection of the proliferative marker Ki-67, the neural-specific intermediate filament Nestin, and doublecortin, a marker for newly differentiated and migrating neuroblasts. Briefly, after quenching in 3\% $\mathrm{H}_{2} \mathrm{O}_{2} / 10 \%$ methanol in $0.1 \mathrm{M}$ PBS for $15 \mathrm{~min}$, and preincubation with the proper sera, the sections were incubated for $48 \mathrm{~h}$ at $4^{\circ} \mathrm{C}$ with a mouse monoclonal antibody against Ki-67 (1:120, Novocastra, Newcastle, UK), a monoclonal mouse anti-rat nestin antibody (1:200, BD Biosciences Pharmingen, Heidelberg, Germany), or a goat anti-doublecortin antibody (1:400, Santa Cruz Biotechnology, Santa Cruz, CA, USA), respectively. The sections were then incubated for $2 \mathrm{~h}$ with the respective secondary antibodies (biotinylated horse anti-mouse, 1:200; Dakopatts, and biotinylated horse anti-goat, 1:200; Vector Laboratories), and visualized as described above.

Immunohistochemistry for the cell cycle marker proliferating cell nuclear antigen (PCNA) was also performed. A separate series of brain sections was first incubated in $10 \mathrm{mM}$ sodium citrate buffer (in PBS, $\mathrm{pH} 6.0$ ) at $95^{\circ} \mathrm{C}$ for $5 \mathrm{~min}$. This step was repeated twice in order to unmask the antigens. After quenching and preincubation with $5 \%$ normal swine serum (NSS) for $1 \mathrm{~h}$, the sections were incubated with a rabbit polyclonal antibody against PCNA (1:200, Santa Cruz Biotechnology) for $48 \mathrm{~h}$ at $4^{\circ} \mathrm{C}$. The sections were then incubated with a biotinylated swine anti-rabbit secondary antibody (Dako), and visualized as described above.

Neuronal differentiation was also assessed by BrdU/neuronal nuclei (NeuN) double labeling. Briefly, after DNA denaturation and preincubation in the proper sera, the sections were incubated for $48 \mathrm{~h}$ at $4^{\circ} \mathrm{C}$ in monoclonal rat anti-BrdU (1:100, ImmunologicalsDirect, Oxfordshire, UK) and mouse anti-NeuN (1:100, Chemicon, Temecula, CA, USA) antibodies. The sections were then incubated with the secondary antibodies Cy3-conjugated donkey anti-rat IgG (1:200, Jackson ImmunoResearch, West Grove, PA, USA) and biotinylated horse anti-mouse IgG (Vector Laboratories) for $2 \mathrm{~h}$, followed by incubation with Alexa-488conjugated streptavidin (1:200, Molecular Probes, Leiden, The Netherlands) for $2 \mathrm{~h}$.

\section{Morphological quantification}

All morphological analyses were performed on blind-coded slides. The numbers of BrdU-, Ki-67-, PCNA-, nestin-, and doublecortin-immunopositive cells in the SGZ of the DG of the dorsal hippocampus were assessed by counting all positive cells in 7 to 9 sections/mouse at the levels of bregma -1.34 to -2.80 using conventional light microscopy with a $40 \times$ objective. The 
distance between the sections was $150 \mu \mathrm{m}$. The total number of cells assessed in 7-9 sections/mouse was expressed as the average number of cells per section. Due to the large number of positive cells in the SVZ, the total number of BrdU- and PCNAlabeled cells in this region was estimated with stereological techniques (Gundersen et al., 1998). We used a 100× objective fitted on an Olympus $\mathrm{BH} 2$ microscope, an $\mathrm{X}-\mathrm{Y}-\mathrm{Z}$ step motor stage run by an IBM PC computer, a CCD-IRIS color video camera, and the CAST-GRID software (Olympus Denmark A/S, Albertslund, Denmark). For systematic sampling, the frame area $\left(163 \mu \mathrm{m}^{2}\right)$ and the counting interval ( $x$ and $y$ both $75 \mu \mathrm{m}$ ) were set to allow for at least a total of 100 cells to be sampled in five sections with the SVZ (ending at the level of bregma 0.14 with the presence of the anterior commissure, and including four anterior sections within one series) and the optical dissector was set to sample all cells below the first $2.5 \mu \mathrm{m}$ and above the last $2.5 \mu \mathrm{m}$ of both surfaces of the section. The total volume of the SVZ was assessed by multiplying the sum of the five areas outlined above with the thickness of the sections $(30 \mu \mathrm{m})$ and the number of series (6), according to stereological principles (Gundersen et al., 1998). For the sections that were processed for BrdU/NeuN immunohistochemistry, 50 BrdU-labeled cells per mouse were analyzed for co-labeling with NeuN, using a confocal laser-scanning microscope (Leica DM IRE3 microscope, Leica Confocal Software Version 2.77) at $1 \mu \mathrm{m}$ optical thickness.

\section{Statistics}

The data were analyzed with a two-factor analysis of variance (ANOVA) or unpaired Student's $t$ tests, when appropriate, using the Statview 5.4 package (Abacus Concepts, Berkeley, CA, USA). Data are presented as mean \pm SEM. A $P$ value of $<0.05$ was considered statistically significant.

\section{Results}

R6/2 mice exhibited decreased hippocampal cell proliferation with increased disease progression

Using BrdU to label dividing cells, we observed an agerelated decline in the number of proliferating cells in mice of both genotypes (Fig. 1). However, compared to wild-type littermates, R6/2 mice exhibited significantly fewer BrdU-labeled cells. Already at 3.5 weeks, R6/2 mice displayed a significant $21 \%$ reduction in the number of BrdU-positive cells compared to wild-type littermates. A trend for a similar reduction (19\%) in the number of nestin-positive cells was detected at this age (wildtype $377 \pm 25$ cells/section, R6/2 $304 \pm 24$ cells/section, Student's $t$ test $P=0.057)$. At 7.5 weeks, an age at which motor symptoms are present, BrdU cell numbers further declined to $43 \%$ compared to wild-type mice. At 11.5 weeks, at a more advanced stage of motor symptoms, R6/2 mice showed a reduction of $66 \%$ in BrdU-labeled cells compared to wild-type mice (Fig. 1).

$\mathrm{Ki}-67$ is a nuclear protein that is expressed in all phases of the cell cycle except the resting phase and can be used as a marker for proliferation in the initial phase of adult neurogenesis (Kee et al., 2002). Therefore, we used this endogenous cell cycle marker to assess cell proliferation in mice younger than 3.5 weeks. We
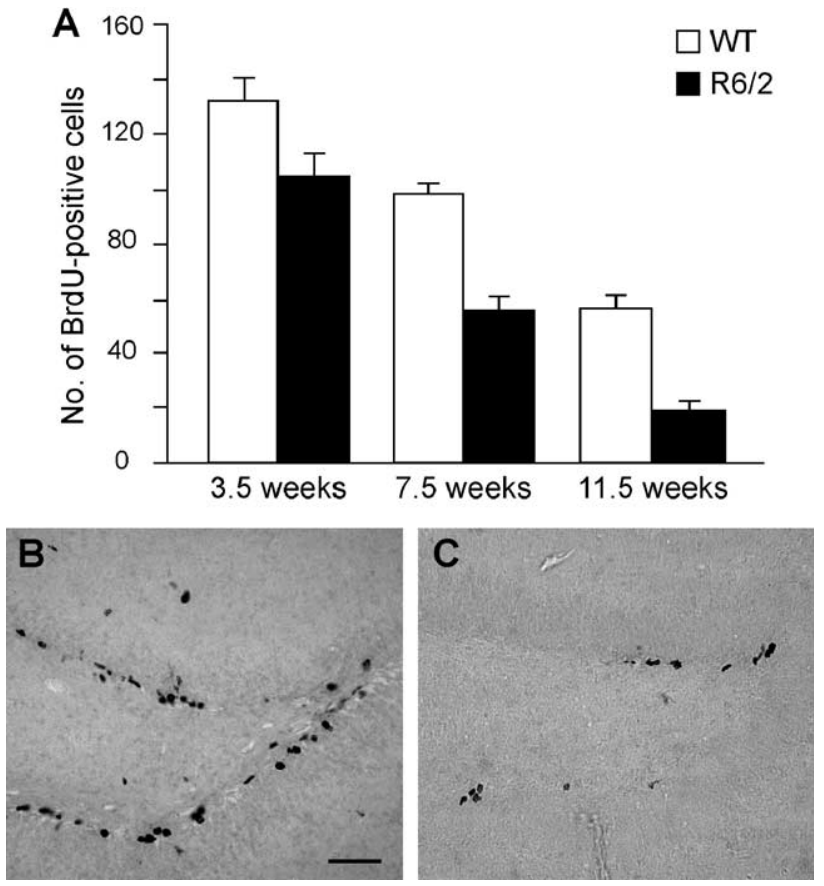

Fig. 1. Progressive reduction in the number of BrdU-labeled cells in the dentate gyrus of R6/2 and wild-type mice. There was an age-related decline in the number of BrdU-labeled cells in the DG of all mice (A). Compared to wild-type littermates, R6/2 mice displayed significantly less BrdU-labeled cells at all ages examined [two-factor ANOVA genotype $F(1,38)=46.97$, $P<0.0001$; age $F(2,38)=80.93, P<0.0001$; age $\times$ genotype $F(2,38)=$ $0.71, P=$ n.s.]. Representative sections of the DG processed for $\mathrm{BrdU}$ immunohistochemistry in wild-type (B) and R6/2 mice (C) at 11.5 weeks of age. Scale bar $=50 \mu \mathrm{m}$.

found a non-significant trend towards a decrease in the number of Ki-67-positive cells (20\% reduction) in 2-week-old R6/2 mice (Fig. 2A). Assessment of Ki-67-positive cells at 11.5 weeks of age confirmed the BrdU analysis, with $72 \%$ fewer Ki-67-labeled cells in R6/2 mice compared to wild-type littermates (Fig. 2). Since the cell cycle marker PCNA has been used in a previous study assessing cell proliferation in human HD tissue (Curtis et al., 2003), we also used this marker to evaluate cell proliferation in R6/2 mice. Again, we observed a non-significant trend towards a decrease in the number of PCNA-labeled cells at the early age of 2 weeks in R6/2 mice (10\% reduction) (Fig. 3A). However, this marker was less sensitive at detecting decreases in cell proliferation at 11.5 weeks of age, since we only observed about a $36 \%$ decrease in the number of PCNA-labeled cells (Fig. 3), compared to $66 \%$ and $72 \%$ with BrdU and Ki-67, respectively.

Decreased hippocampal neurogenesis both at early and at end stage of disease in R6/2 mice

Three-and-a-half-week-old and 8-week-old mice were injected with BrdU (every $12 \mathrm{~h}$, during 3 days) and allowed to survive for an additional 2 weeks before being sacrificed. The total number of BrdU-labeled cells 2 weeks after the last BrdU injection was significantly smaller in R6/2 compared to wild-type mice at both timepoints (Fig. 4A). Interestingly, if the average number of BrdU-labeled cells/section/genotype at 5.5 weeks (2 weeks postinjection) was compared with the numbers at 3.5 weeks $(18 \mathrm{~h}$ 

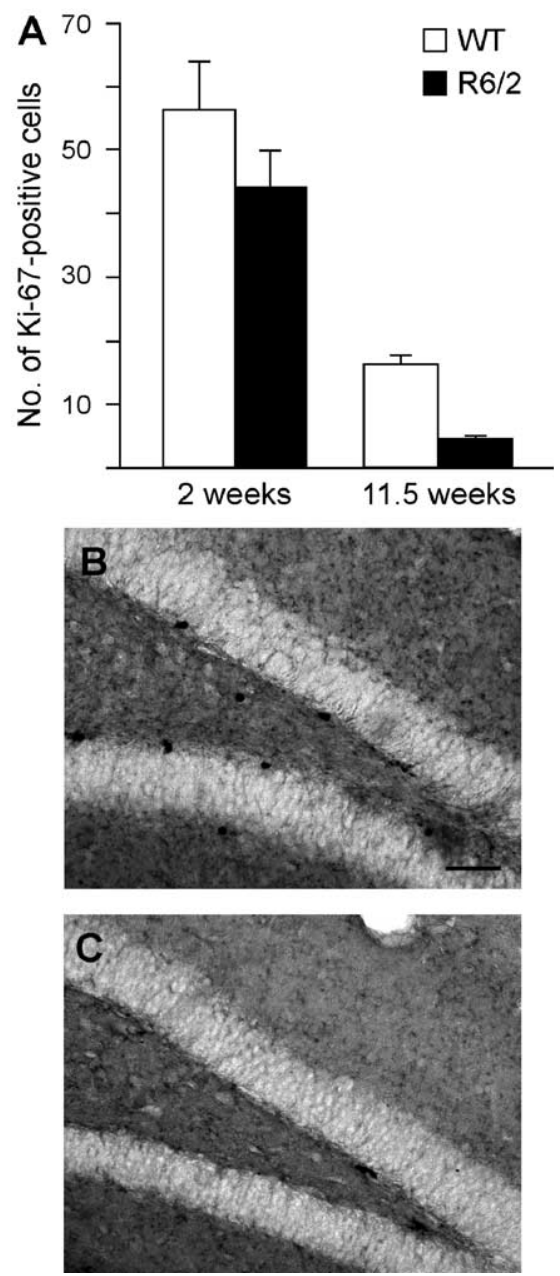

Fig. 2. Reduced cell proliferation in the R6/2 dentate gyrus as assessed with the endogenous cell proliferation marker Ki-67. There was a progressive reduction in Ki-67-positive cells in the DG of both R6/2 and wild-type mice (A). The R6/2 mice displayed significantly fewer Ki-67-positive cells [twofactor ANOVA genotype $F(1,22)=6.83, P<0.05$; age $F(1,22)=198.97$, $P<0.0001$; age $\times$ genotype $F(1,22)=0.61, P=$ n.s. $]$. Representative photomicrographs of the DG processed for Ki-67 immunohistochemistry in wild-type (B) and R6/2 mice (C) at 11.5 weeks of age. Scale bar $=50 \mu \mathrm{m}$.

post-injection), there were $35 \%$ less BrdU-positive cells in wildtype and $69 \%$ less BrdU-positive cells in R6/2 mice at 5.5 weeks of age. Similarly, if the average number of BrdU-labeled cells/ section/genotype at 10 weeks (2 weeks post-injection) was compared with the numbers at 7.5 weeks (18 h post-injection), there were $73 \%$ less BrdU-positive cells in wild-type and $84 \%$ less BrdU-positive cells in R6/2 mice at 10 weeks of age. The procedure of waiting 2 weeks after the last BrdU injection allowed us to determine the phenotype of the BrdU-positive cells. By using confocal analysis, we estimated that about $80-90 \%$ of the remaining BrdU-labeled cells co-expressed the specific neuronal marker NeuN at both 5.5 and 10 weeks of age (Figs. $4 \mathrm{~B}$ and $\mathrm{C}$ ). In the 10-week-old mice, we observed a significant $65 \%$ decrease in the number of cells immunopositive for doublecortin, a microtubule binding protein that is expressed in newly differentiated and migrating neuroblasts (Brown et al., 2003), further confirming the reduced neurogenesis in R6/2 mice (Fig. 5).
R6/2 mice exhibit normal proliferation in the subventricular zone

We began by evaluating the volume of the SVZ, another neurogenic zone in the adult brain, in young and old R6/2 and wild-type mice. The total volume of the SVZ was $0.072 \pm 0.004$ $\mathrm{mm}^{3}$ in wild-type and $0.072 \pm 0.003 \mathrm{~mm}^{3}$ in R6/2 mice at 3.5 weeks, and $0.071 \pm 0.003 \mathrm{~mm}^{3}$ in wild-type and $0.057 \pm 0.003$ $\mathrm{mm}^{3}$ in R6/2 mice at 11.5 weeks of age (two-factor ANOVA revealed a significant difference between the age groups $[F(1,26)=5.28, P<0.05]$, but no difference between the genotypes $[F(1,26)=4.17$, n.s. $]$, nor any interaction between age and genotype $[F(1,26)=4.08$, n.s. $])$. We then examined the total number of BrdU-labeled cells in this region and found no significant differences between R6/2 and wild-type mice at either 3.5 or 11.5 weeks of age (Figs. $6 \mathrm{~A}-\mathrm{C}$ ). Furthermore, the total number of PCNA-positive cells in the SVZ did not differ between R6/2 and wild-type mice at 11.5 weeks of age (Figs. 6D-F).
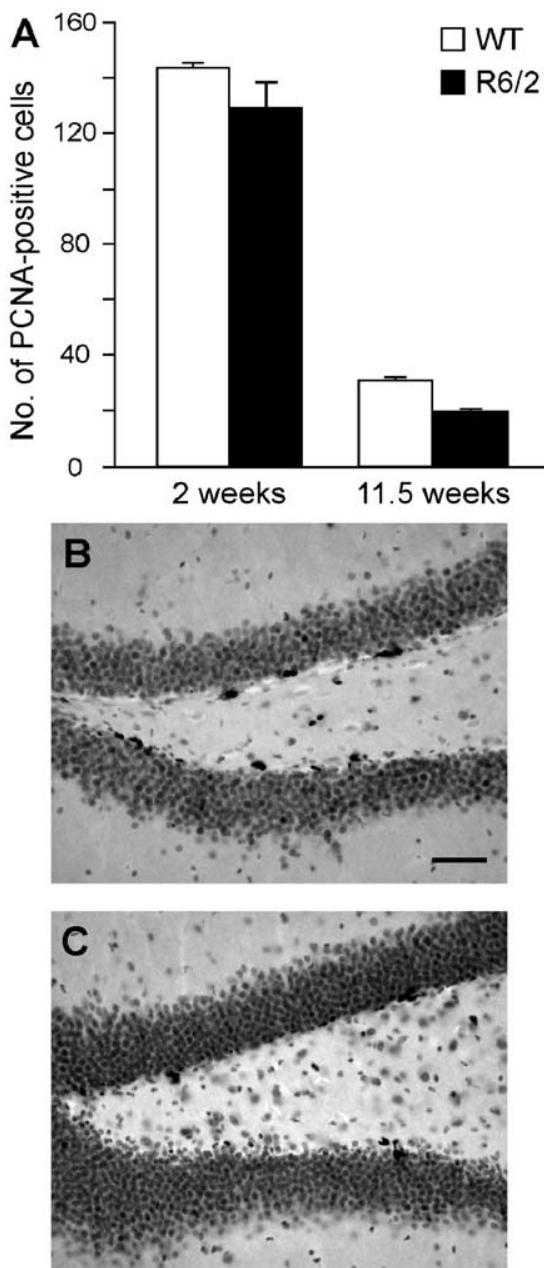

Fig. 3. Reduced cell proliferation in the R6/2 dentate gyrus as assessed with the cell cycle marker PCNA. There was a progressive decrease in the number of PCNA-immunopositive cells with increasing age in the DG of both R6/2 and wild-type mice (A). Significantly fewer PCNA-positive cells were found in R6/2 mice [two-factor ANOVA genotype $F(1,22)=11.04$, $P<0.005$; age $F(1,22)=840.09, P<0.0001$; age $\times$ genotype $F(1,22)=$ $0.21, P=$ n.s.]. Representative sections of the DG processed for PCNA immunohistochemistry in wild-type (B) and R6/2 mice (C) at 11.5 weeks of age. Scale bar $=50 \mu \mathrm{m}$. 


\section{Discussion}

Neurogenesis occurs continuously in two specific regions of the adult brain, the SVZ and the SGZ of the DG in the hippocampus (for review, see Lie et al., 2004). Although the functional impact of adult neurogenesis in the hippocampus is not yet known (Kempermann et al., 2004), it has been suggested to be involved in important neuronal functions such as learning and memory (van
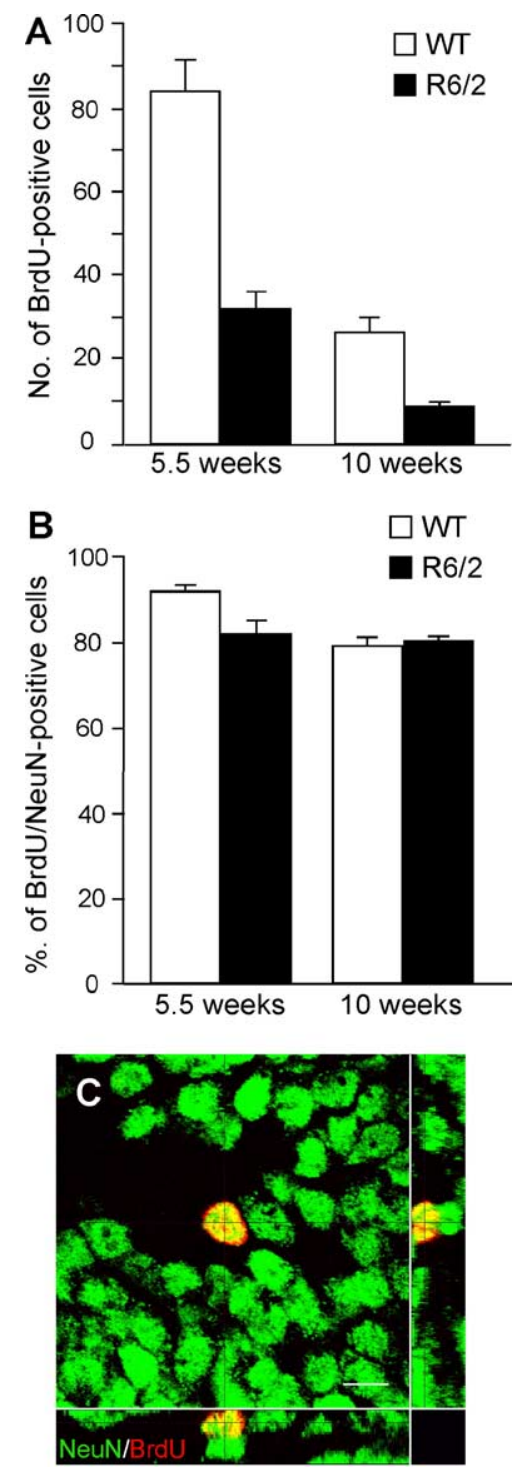

Fig. 4. Decreased hippocampal neurogenesis in R6/2 mice. To study whether the reduced cell proliferation reflected a decrease in neurogenesis, 5.5- and 10-week-old mice were sacrificed 2 weeks after the last BrdU injection to allow for differentiation of the proliferating cells that incorporated BrdU. A significant reduction in BrdU-labeled cells was found in the DG of the R6/2 mice at both timepoints compared to wild-type mice (A) [two-factor ANOVA genotype $F(1,17)=52.75, P<0.0001$; age $F(1,17)=72.46, P<0.0001 ;$ genotype $\times$ age $F(1,17)=12.99, P<0.005]$. In the DG of both 5.5- and 10-week-old wild-type and R6/2 mice, around $80-90 \%$ of the BrdU-labeled cells were NeuN-positive (B) [two-factor ANOVA genotype $F(1,17)=3.50, P=$ n.s.; age $F(1,17)=9.85, P<0.01$; age $\times$ genotype $F(1,17)=6.87, P<0.05]$. A representative confocal image of a cell immunopositive for both BrdU (red) and NeuN (green) in the DG of a 10-week-old R6/2 mouse (C). Scale bar $=8 \mu \mathrm{m}$.
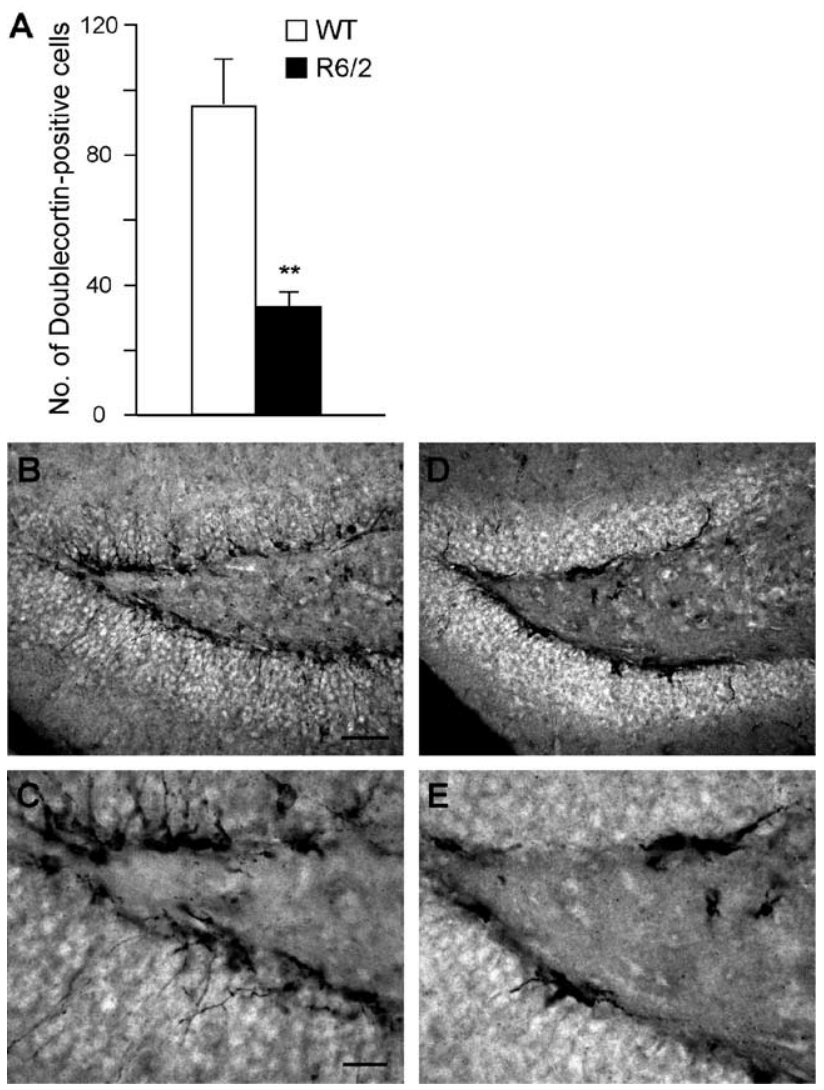

Fig. 5. Decreased number of neuroblasts in the dentate gyrus of 10 -weekold R6/2 mice. The reduced hippocampal neurogenesis in R6/2 mice was confirmed by a significant decrease in the number of doublecortinimmunopositive neuroblasts in the DG of 10 -week-old R6/2 mice as compared to wild-type controls (Student's $t$ test, $P<0.01$ ) (A). Representative photomicrographs of the DG processed for doublecortin immunohistochemistry in wild-type $(B, C)$ and $R 6 / 2$ mice $(D, E)$ at 10 weeks of age. Scale bar $=50 \mu \mathrm{m}(\mathrm{B}, \mathrm{D}), 20 \mu \mathrm{m}(\mathrm{C}, \mathrm{E})$.

Praag et al., 2002). Recent studies indicate that damage to surrounding brain regions can induce proliferation, migration, and maturation of these neural precursors (Arvidsson et al., 2002; Fallon et al., 2000; Parent et al., 2002). Impaired neurogenesis may play a role in the pathogenesis of neurodegenerative disorders and possibilities of restoring brain function by promoting neurogenesis have emerged as potential therapeutic options (for reviews, see Armstrong and Barker, 2001; Lie et al., 2004; Mohapel and Brundin, 2004).

In this study, we report an age-related decline in hippocampal cell proliferation, both in R6/2 mice and in wild-type littermates. The progressive reduction in hippocampal cell proliferation in wild-type mice is in agreement with a previous report showing reduced cell proliferation in the rodent DG with aging (Bizon and Gallagher, 2003). Importantly, R6/2 mice exhibited a more dramatic reduction of proliferating BrdU-positive cells with age than wild-type mice. Lazic and coworkers have recently shown a decrease in hippocampal cell proliferation in R6/1 HD mice (Lazic et al., 2004), and we previously reported a 70\% reduction in BrdUlabeled cells in the R6/2 hippocampus at 12 weeks of age (Gil et al., 2004). In the present study, we extended the investigation by establishing the progressive nature of the reduced cell proliferation using different cell cycle markers such as BrdU, Ki-67, and PCNA. Furthermore, we found that the reduced cell proliferation indeed 

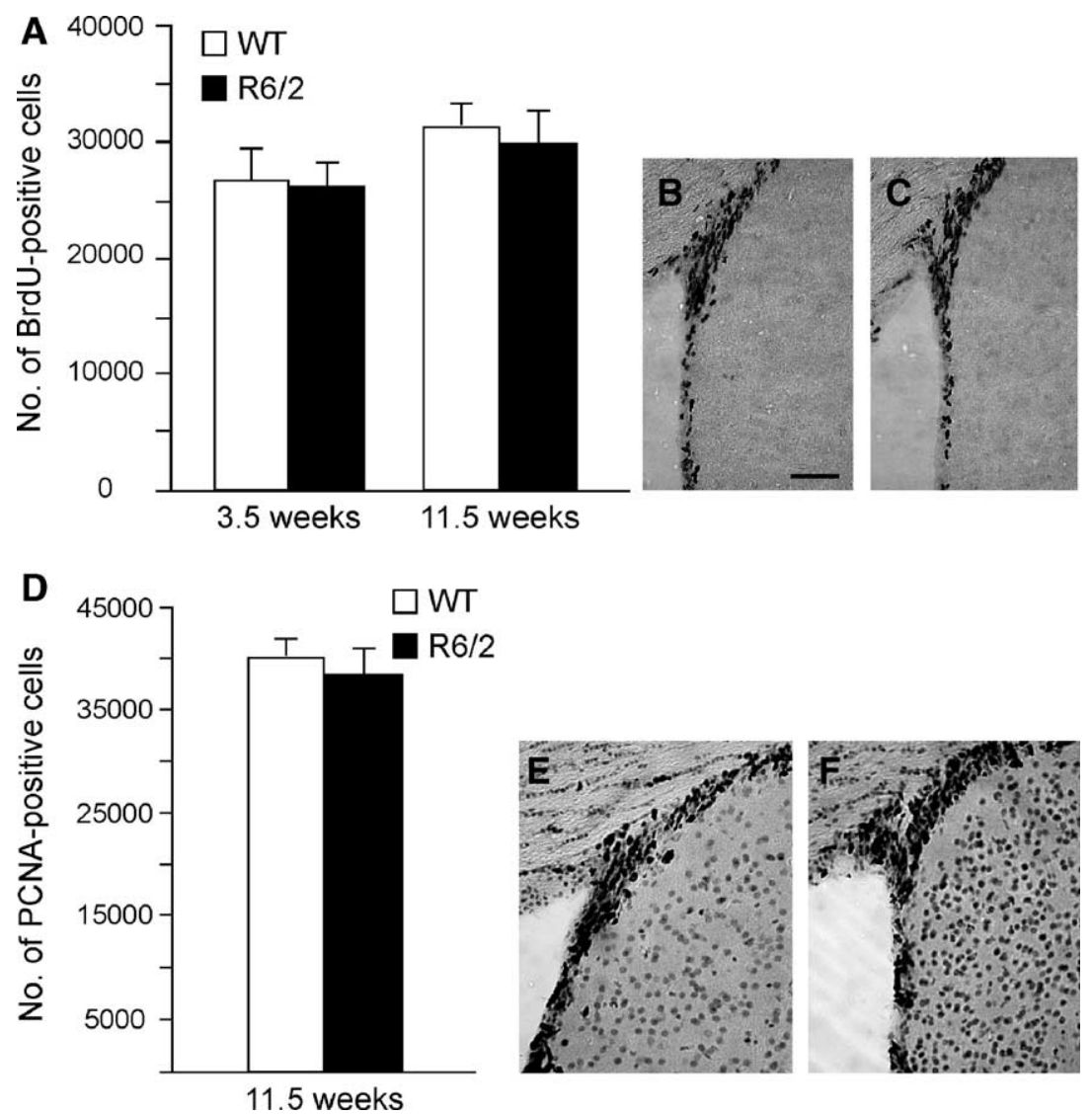

Fig. 6. No difference in cell proliferation in the subventricular zone between R6/2 mice and wild-type littermates. Cell proliferation in the SVZ of 3.5- and 11.5week-old R6/2 mice and wild-type littermates was examined using stereological assessments of BrdU-labeled cells (A). The number of proliferating cells increased with age [two-factor ANOVA $F(1,26)=4.98, P<0.04]$ but no differences were found between the genotypes $[F(1,26)=0.64, P=$ n.s. $]$ nor was there an interaction between age and genotype $[F(1,26)=0.04, P=$ n.s.]. Representative sections of the SVZ processed for BrdU immunohistochemistry in wild-type (B) and R6/2 mice (C) at 11.5 weeks of age. Scale bar $=100 \mu \mathrm{m}$. The cell cycle marker PCNA was also used to assess cell proliferation in the SVZ of 11.5-week-old R6/2 mice (D). Again, no significant difference in the number of PCNA-positive cells was detected between the two genotypes (Student's $t$ test, $P=$ n.s.). Representative photomicrographs of the SVZ processed for PCNA immunohistochemistry in wild-type (E) and R6/2 mice (F) at 11.5 weeks of age. Scale bar $=100 \mu$ m.

represented a decreased neurogenesis. Approximately $80-90 \%$ of the surviving BrdU-labeled cells became neurons in both wild-type and R6/2 mice, which is a similar percentage to what has been reported previously (Duman et al., 2000). The study by Lazic et al., however, failed to detect any cells co-labeled for BrdU and NeuN in R6/1 mice (Lazic et al., 2004). We found a reduction in BrdUlabeled cells during the 2 weeks after the last injection. The massive reduction in the number of BrdU-labeled cells commonly reported after the first days up to more than 2 weeks post-injection is thought to be due to cell death (Dayer et al., 2003; Gould et al., 1999).

Cell loss in the hippocampus of HD patients has been reported in a few cases (Rosas et al., 2003; Vonsattel and DiFiglia, 1998). However, no neuronal loss in the DG of the hippocampus occurs in 12-week-old R6/2 mice as assessed by stereology (Gil et al., 2004) and Fluoro-Jade staining (Gil et al., unpublished observations). Nonetheless, there is strong electrophysiological and behavioral evidence for hippocampal dysfunction (Murphy et al., 2000). Disturbed neurogenesis could be involved in this dysfunction.

Emerging evidence suggests that the expanded polyglutamine in huntingtin can alter protein-protein interactions and thereby interfere with vital cell functions ( $\mathrm{Li}$ and $\mathrm{Li}, 2004$ ). In a parallel study, we detected a reduced number of BrdU-labeled cells in pancreatic islets of 12-week-old R6/2 mice (Björkqvist et al., 2005). Evidence to link these two events arises from a recent study showing that normal huntingtin and the huntingtin-associated proteins huntingtin-associated protein 1 and mixed-lineage kinase 2 modulate and stimulate the activity of the helix-loop-helix transcription factor NeuroD (Marcora et al., 2003). NeuroD is expressed in the pancreas, where it plays a crucial role in the morphogenesis of normal islets (Huang et al., 2002), and in the development of the DG (Liu et al., 2000). This relationship between normal huntingtin, NeuroD, and genesis of new cells raises the exciting possibility that an abnormal interaction between mutant huntingtin and NeuroD could contribute, at least in part, to the compromised generation of new cells observed both in the DG and in the pancreas of R6/2 HD mice.

The underlying mechanism for the reduced neurogenesis in R6/ 2 mice is however not known. Interestingly, brain-derived neurotrophic factor (BDNF), which stimulates cell proliferation in the neurogenic zones (Benraiss et al., 2001; Pencea et al., 2001), is down-regulated in HD (Canals et al., 2004; Luthi-Carter et al., 2002; Spires et al., 2004; Zuccato et al., 2001). The dopaminergic system, recently implicated in the regulation of neurogenesis (Hoglinger et al., 2004), is also affected in HD. Experimental depletion of dopamine in rodents decreased cell proliferation in the DG and the SVZ and a selective agonist of D2-like receptors was enough to completely restore proliferation (Hoglinger et al., 2004). R6 mice display a deficient dopaminergic transmission (Bibb et al., 
2000; Petersén et al., 2002), and both transgenic HD mice and HD patients express reduced levels of tyrosine hydroxylase (Yohrling et al., 2003) and a loss of D2 receptors (Cha et al., 1998; Weeks et al., 1996). Whether reduction in BDNF levels or dysfunction in the dopaminergic neurotransmission contributes to the observed compromised neurogenesis in R6/2 mice remains to be evaluated.

In contrast to the decrease in cell proliferation/neurogenesis in the R6/2 DG, we again observed no difference in the number of proliferating cells in the SVZ between R6/2 and wild-type mice (Gil et al., 2004). This is in contrast to findings in HD patients where increased cell proliferation estimated by PCNA immunohistochemistry has been reported (Curtis et al., 2003). This discrepancy could be due to factors such as a higher number of CAG repeats and greater frequency of inclusions in R6/2 mice than in HD patients. Moreover, it has been suggested that PCNA is expressed in cells undergoing DNA repair (Tomasevic et al., 1998). Although BrdU may be incorporated in any cell undergoing DNA synthesis, a careful study by Cooper-Kuhn and Kuhn demonstrated that the concentration in which BrdU is commonly used $(50 \mathrm{mg} / \mathrm{kg})$ is not sufficient to detect cells undergoing DNA repair (Cooper-Kuhn and Kuhn, 2002). Further analysis of HD brains using a combination of several proliferative markers is therefore warranted.

In conclusion, hippocampal neurogenesis may be a new outcome parameter to assess the efficacy of potential therapies in the R6/2 HD transgenic mouse model, even though the underlying mechanism causing a reduction is not yet known. Since neurogenesis may play a role in hippocampal function, it is possible that therapies aimed to restore hippocampal cell proliferation are beneficial.

\section{Acknowledgments}

We are grateful to Britt Lindberg, Birgit Haraldsson, Bengt Mattsson, and Elsy Ling for excellent technical assistance. We also thank Eduardo Marcoro for helpful discussions. JG has a fellowship from the Foundation for Science and Technology (FCT, Portugal; $\mathrm{SFRH/BD/6068/2001).} \mathrm{IMA} \mathrm{is} \mathrm{supported} \mathrm{by} \mathrm{a} \mathrm{short} \mathrm{term} \mathrm{fellowship}$ from the Federation of European Biochemical Societies (FEBS). NP is supported by the grant Biodegradable controlled drug delivery systems for the treatment of brain diseases (BCDDS)(QLRT-200002226); RTD-EU-project, Quality of Life and Management of Living Resources. ÅP is supported by the Swedish Brain Foundation. PB is supported by the Swedish Research Council and the Hereditary Disease Foundation. PM was supported by Neuronova AB. JG, NP, J-YL, ÅP, and PB are members of The European Union concerted action consortium "Early Pathogenetic Markers for Slow Neurodegenerative Diseases" (EPSND, QLK6-CT-2000-00384) and would like to acknowledge the helpful discussions that have taken place within this network.

\section{References}

Armstrong, R.J., Barker, R.A., 2001. Neurodegeneration: a failure of neuroregeneration? Lancet 358, 1174-1176.

Arvidsson, A., Collin, T., Kirik, D., Kokaia, Z., Lindvall, O., 2002. Neuronal replacement from endogenous precursors in the adult brain after stroke. Nat. Med. 8, 963-970.

Benraiss, A., Chmielnicki, E., Lerner, K., Roh, D., Goldman, S.A., 2001. Adenoviral brain-derived neurotrophic factor induces both neostriatal and olfactory neuronal recruitment from endogenous progenitor cells in the adult forebrain. J. Neurosci. 21, 6718-6731.
Bibb, J.A., Yan, Z., Svenningsson, P., Snyder, G.L., Pieribone, V.A., Horiuchi, A., Nairn, A.C., Messer, A., Greengard, P., 2000. Severe deficiencies in dopamine signaling in presymptomatic Huntington's disease mice. Proc. Natl. Acad. Sci. U. S. A. 297, 6809-6814.

Bizon, J.L., Gallagher, M., 2003. Production of new cells in the rat dentate gyrus over the lifespan: relation to cognitive decline. Eur. J. Neurosci. $18,215-219$.

Björkqvist, M., Fex, M., Wierup, N., Petersén, Å., Gil, J., Bacos, K., Popovic, N., Li, J.Y., Sundler, F., Brundin, P., Mulder, H., 2005. The R6/2 transgenic mouse model of Huntington's disease develops diabetes due to deficient $\beta$-cell mass. Hum. Mol. Genet. 14, 565-574.

Brown, J.P., Couillard-Despres, S., Cooper-Kuhn, C.M., Winkler, J., Aigner, L., Kuhn, H.G., 2003. Transient expression of doublecortin during adult neurogenesis. J. Comp. Neurol. 467, 1-10.

Canals, J.M., Pineda, J.R., Torres-Peraza, J.F., Bosch, M., Martin-Ibanez, R., Munoz, M.T., Mengod, G., Ernfors, P., Alberch, J., 2004. Brainderived neurotrophic factor regulates the onset and severity of motor dysfunction associated with enkephalinergic neuronal degeneration in Huntington's disease. J. Neurosci. 24, 7727-7739.

Carter, R.J., Lione, L.A., Humby, T., Mangiarini, L., Mahal, A., Bates, G.P., Dunnett, S.B., Morton, A.J., 1999. Characterization of progressive motor deficits in mice transgenic for the human Huntington's disease mutation. J. Neurosci. 19, 3248-3257.

Cha, J.H., 2000. Transcriptional dysregulation in Huntington's disease. Trends Neurosci. 23, 387-392.

Cha, J.H., Kosinski, C.M., Kerner, J.A., Alsdorf, S.A., Mangiarini, L., Davies, S.W., Penney, J.B., Bates, G.P., Young, A.B., 1998. Altered brain neurotransmitter receptors in transgenic mice expressing a portion of an abnormal human huntington disease gene. Proc. Natl. Acad. Sci. U. S. A. $95,6480-6485$.

Cooper-Kuhn, C.M., Kuhn, H.G., 2002. Is it all DNA repair? Methodological considerations for detecting neurogenesis in the adult brain. Brain Res. Dev. Brain Res. 134, $13-21$.

Curtis, M.A., Penney, E.B., Pearson, A.G., van Roon-Mom, W.M., Butterworth, N.J., Dragunow, M., Connor, B., Faull, R.L., 2003. Increased cell proliferation and neurogenesis in the adult human Huntington's disease brain. Proc. Natl. Acad. Sci. U. S. A. 100, 9023-9027.

Davies, S.W., Turmaine, M., Cozens, B.A., DiFiglia, M., Sharp, A.H., Ross, C.A., Scherzinger, E., Wanker, E.E., Mangiarini, L., Bates, G.P., 1997. Formation of neuronal intranuclear inclusions underlies the neurological dysfunction in mice transgenic for the HD mutation. Cell 90, 537-548.

Dayer, A.G., Ford, A.A., Cleaver, K.M., Yassaee, M., Cameron, H.A., 2003. Short-term and long-term survival of new neurons in the rat dentate gyrus. J. Comp. Neurol. 460, 563-572.

Duman, R.S., Malberg, J., Nakagawa, S., 2000. Regulation of adult neurogenesis by psychotropic drugs and stress. J. Pharmacol. Exp. Ther. 299, 401-407.

Fallon, J., Reid, S., Kinyamu, R., Opole, I., Opole, R., Baratta, J., Korc, M., Endo, T.L., Duong, A., Nguyen, G., Karkehabadhi, M., Twardzik, D., Patel, S., Loughlin, S., 2000. In vivo induction of massive proliferation, directed migration, and differentiation of neural cells in the adult mammalian brain. Proc. Natl. Acad. Sci. U. S. A. 97, 14686-14691.

Frielingsdorf, H., Schwarz, K., Brundin, P., Mohapel, P., 2004. No evidence for new dopaminergic neurons in the adult mammalian substantia nigra. Proc. Natl. Acad. Sci. U. S. A. 101, 10177-10182.

Gil, J.M., Leist, M., Popovic, N., Brundin, P., Petersén, Å., 2004. Asialoerythropoietin is not effective in the R6/2 line of Huntington's disease mice. BMC Neurosci. 5, 1-10.

Gould, E., Beylin, A., Tanapat, P., Reeves, A., Shors, T.J., 1999. Learning enhances adult neurogenesis in the hippocampal formation. Nat. Neurosci. 2, 260-265.

Gundersen, H.J., Bendtsen, T.F., Korbo, L., Marcussen, N., Moller, A., Nielsen, K., Nyengaard, J.R., Pakkenberg, B., Sorensen, F.B., Vesterby, A., West, M.J., 1998. Some new, simple and efficient stereological methods and their use in pathological research and diagnosis. APMIS 96, 379-394.

Haughey, N.J., Liu, D., Nath, A., Borchard, A.C., Mattson, M.P., 2002a. 
Disruption of neurogenesis in the subventricular zone of adult mice, and in human cortical neuronal precursor cells in culture, by amyloid betapeptide: implications for the pathogenesis of Alzheimer's disease. Neuromolecular Med. 1, 125-135.

Haughey, N.J., Nath, A., Chan, S.L., Borchard, A.C., Rao, M.S., Mattson, M.P., 2002b. Disruption of neurogenesis by amyloid beta-peptide, and perturbed neural progenitor cell homeostasis, in models of Alzheimer's disease. J. Neurochem. 83, 1509-1524.

Helmlinger, D., Yvert, G., Picaud, S., Merienne, K., Sahel, J., Mandel, J.L., Devys, D., 2002. Progressive retinal degeneration and dysfunction in R6 Huntington's disease mice. Hum. Mol. Genet. 11, 3351-3359.

Hoglinger, G.U., Rizk, P., Muriel, M.P., Duyckaerts, C., Oertel, W.H., Caille, I., Hirsch, E.C., 2004. Dopamine depletion impairs precursor cell proliferation in Parkinson disease. Nat. Neurosci. 7, 726-735.

Huang, H.P., Chu, K., Nemoz-Gaillard, E., Elberg, D., Tsai, M.J., 2002. Neogenesis of beta-cells in adult BETA2/NeuroD-deficient mice. Mol. Endocrinol. 16, 541-551.

Iannicola, C., Moreno, S., Oliverio, S., Nardacci, R., Ciofi-Luzzatto, A., Piacentini, M., 2000. Early alterations in gene expression and cell morphology in a mouse model of Huntington's disease. J. Neurochem. $75,830-839$.

Jin, K., Peel, A.L., Mao, X.O., Xie, L., Cottrell, B.A., Henshall, D.C., Greenberg, D.A., 2004a. Increased hippocampal neurogenesis in Alzheimer's disease. Proc. Natl. Acad. Sci. U. S. A. 101, 343-347.

Jin, K., Galvan, V., Xie, L., Mao, X.O., Gorostiza, O.F., Bredesen, D.E., Greenberg, D.A., 2004b. Enhanced neurogenesis in Alzheimer's disease transgenic mice. Proc. Natl. Acad. Sci. U. S. A. 101, 13363-13367.

Kee, N., Sivalingam, S., Boonstra, R., Wojtowicz, J.M., 2002. The utility of $\mathrm{Ki}-67$ and BrdU as proliferative markers of adult neurogenesis. J. Neurosci. Methods 115, 97-105.

Kempermann, G., Wiskott, L., Gage, F.H., 2004. Functional significance of adult neurogenesis. Curr. Opin. Neurobiol. 14, 186-191.

Lazic, S.E., Grote, H., Armstrong, R.J., Blakemore, C., Hannan, A.J., van Dellen, A., Barker, R.A., 2004. Decreased hippocampal cell proliferation in R6/1 Huntington's mice. NeuroReport 15, 811-813.

Li, S.H., Li, X.J., 2004. Huntingtin-protein interactions and the pathogenesis of Huntington's disease. Trends Genet. 20, 146-154.

Lie, D.C., Song, H., Colamarino, S.A., Ming, G.L., Gage, F.H., 2004. Neurogenesis in the adult brain: new strategies for central nervous system diseases. Annu. Rev. Pharmacol. Toxicol. 44, 399-421.

Lione, L.A., Carter, R.J., Hunt, M.J., Bates, G.P., Morton, A.J., Dunnett, S.B., 1999. Selective discrimination learning impairments in mice expressing the human Huntington's disease mutation. J. Neurosci. 19, $10428-10437$.

Liu, M., Pleasure, S.J., Collins, A.E., Noebels, J.L., Naya, F.J., Tsai, M.J., Lowenstein, D.H., 2000. Loss of BETA2/NeuroD leads to malformation of the dentate gyrus and epilepsy. Proc. Natl. Acad. Sci. U. S. A. 97, $865-870$.

Luthi-Carter, R., Strand, A., Peters, N.L., Solano, S.M., Hollingsworth, Z.R., Menon, A.S., Frey, A.S., Spektor, B.S., Penney, E.B., Schilling, G., Ross, C.A., Borchelt, D.R., Tapscott, S.J., Young, A.B., Cha, J.H., Olson, J.M., 2000. Decreased expression of striatal signaling genes in a mouse model of Huntington's disease. Hum. Mol. Genet. 9, 1259-1271.

Luthi-Carter, R., Hanson, S.A., Strand, A.D., Bergstrom, D.A., Chun, W., Peters, N.L., Woods, A.M., Chan, E.Y., Kooperberg, C., Krainc, D., Young, A.B., Tapscott, S.J., Olson, J.M., 2002. Dysregulation of gene expression in the R6/2 model of polyglutamine disease: parallel changes in muscle and brain. Hum. Mol. Genet. 11, 1911-1926.

Mangiarini, L., Sathasivam, K., Seller, M., Cozens, B., Harper, A., Hetherington, C., Lawton, M., Trottier, Y., Lehrach, H., Davies, S.W., Bates, G.P., 1996. Exon 1 of the HD gene with an expanded CAG repeat is sufficient to cause a progressive neurological phenotype in transgenic mice. Cell 87, 493-506.

Mangiarini, L., Sathasivam, K., Mahal, A., Mott, R., Seller, M., Bates, G.P., 1997. Instability of highly expanded CAG repeats in mice transgenic for the Huntington's disease mutation. Nat. Genet. 15, 197-200.

Marcora, E., Gowan, K., Lee, J.E., 2003. Stimulation of NeuroD activity by huntingtin and huntingtin-associated proteins HAP1 and MLK2. Proc. Natl. Acad. Sci. U. S. A. 100, 9578-9583.

Mohapel, P., Brundin, P., 2004. Harnessing endogenous stem cells to treat neurodegenerative disorders of the basal ganglia. Parkinsonism Relat. Disord. 10, 259-264.

Murphy, K.P., Carter, R.J., Lione, L.A., Mangiarini, L., Mahal, A., Bates, G.P., Dunnett, S.B., Morton, A.J., 2000. Abnormal synaptic plasticity and impaired spatial cognition in mice transgenic for exon 1 of the human Huntington's disease gene. J. Neurosci. 20, 5115-5123.

Parent, J.M., Vexler, Z.S., Gong, C., Derugin, N., Ferriero, D.M., 2002. Rat forebrain neurogenesis and striatal neuron replacement after focal stroke. Ann. Neurol. 52, 802-813.

Pencea, V., Bingaman, K.D., Wiegand, S.J., Luskin, M.B., 2001. Infusion of brain-derived neurotrophic factor into the lateral ventricle of the adult rat leads to new neurons in the parenchyma of the striatum, septum, thalamus, and hypothalamus. J. Neurosci. 21, 6706-6717.

Petersén, Å., Brundin, P., 2002. Huntington's disease: the mystery unfolds? Int. Rev. Neorobiol. 53, 315-339.

Petersén, Å., Puschban, Z., Lotharius, J., NicNiocaill, B., Wiekop, P., O'Connor, W.T., Brundin, P., 2002. Evidence for dysfunction of the nigrostriatal pathway in the R6/1 line of transgenic Huntington's disease mice. Neurobiol. Dis. 11, 134-146.

Petersén, Å., Gil, J., Maat-Schieman, M.L.C., Björkqvist, M., Tanila, H., Araújo, I.M., Smith, R., Popovic, N., Wierup, N., Norlén, P., Li, J.-Y., Roos, R.A.C., Sundler, F., Mulder, H., Brundin, P., 2005. Orexin loss in Huntington's disease. Hum. Mol. Genet. 14, 39-47.

Rosas, H.D., Koroshetz, W.J., Chen, Y.I., Skeuse, C., Vangel, M., Cudkowicz, M.E., Caplan, K., Marek, K., Seidman, L.J., Makris, N., Jenkins, B.G., Goldstein, J.M., 2003. Evidence for more widespread cerebral pathology in early HD: an MRI-based morphometric analysis. Neurology 60, 1615-1620.

Spires, T.L., Grote, H.E., Varshney, N.K., Cordery, P.M., van Dellen, A., Blakemore, C., Hannan, A.J., 2004. Environmental enrichment rescues protein deficits in a mouse model of Huntington's disease, indicating a possible disease mechanism. J. Neurosci. 24, 2270-2276.

The Huntington's Disease Collaborative Research Group, 1993. A novel gene containing a trinucleotide repeat that is expanded and unstable on Huntington's disease chromosomes. Cell 72, 971-983.

Tomasevic, G., Kamme, F., Wieloch, T., 1998. Changes in proliferating cell nuclear antigen, a protein involved in DNA repair, in vulnerable hippocampal neurons following global cerebral ischemia. Brain Res. Mol. Brain Res. 60, 168-176.

Turmaine, M., Raza, A., Mahal, A., Mangiarini, L., Bates, G.P., Davies, S.W., 2000. Nonapoptotic neurodegeneration in a transgenic mouse model of Huntington's disease. Proc. Natl. Acad. Sci. U. S. A. 97, 8093-8097.

van Praag, H., Schinder, A.F., Christie, B.R., Toni, N., Palmer, T.D., Gage, F.H., 2002. Functional neurogenesis in the adult hippocampus. Nature $415,1030-1034$.

Vonsattel, J.P., DiFiglia, M., 1998. Huntington disease. J. Neuropathol. Exp. Neurol. 57, 369-384.

Weeks, R.A., Piccini, P., Harding, A.E., Brooks, D.J., 1996. Striatal D1 and D2 dopamine receptor loss in asymptomatic mutation carriers of Huntington's disease. Ann. Neurol. 40, 49-54.

Yohrling IV, G.J., Jiang, G.C., DeJohn, M.M., Miller, D.W., Young, A.B., Vrana, K.E., Cha, J.H., 2003. Analysis of cellular, transgenic and human models of Huntington's disease reveals tyrosine hydroxylase alterations and substantia nigra neuropathology. Brain Res. Mol. Brain Res. 119, 28-36.

Zhao, M., Momma, S., Delfani, K., Carlen, M., Cassidy, R.M., Johansson, C.B., Brismar, H., Shupliakov, O., Frisen, J., Janson, AM., 2003. Evidence for neurogenesis in the adult mammalian substantia nigra. Proc. Natl. Acad. Sci. U. S. A. 100, 7925-7930.

Zuccato, C., Ciammola, A., Rigamonti, D., Leavitt, B.R., Goffredo, D., Conti, L., MacDonald, M.E., Friedlander, R.M., Silani, V., Hayden, M.R., Timmusk, T., Sipione, S., Cattaneo, E., 2001. Loss of huntingtinmediated BDNF gene transcription in Huntington's disease. Science 293, 493-498. 